\title{
Space allowance influences individually housed Holstein male calves' age at feed consumption, standing behaviors, and measures of immune resilience before and after step-down weaning
}

\author{
L. E. Hulbert, ${ }^{1 *}$ M. S. Calvo-Lorenzo, ${ }^{1} \dagger$ M. A. Ballou, ${ }^{2}$ K. C. Klasing, ${ }^{1}$ and F. M. Mitloehner ${ }^{1} \ddagger$ \\ ${ }^{1}$ Department of Animal Science, University of California, Davis 95616 \\ ${ }^{2}$ Department of Animal and Food Sciences, Texas Tech University, Lubbock 79409
}

\section{ABSTRACT}

Many dairy calves in the southwestern regions of the United States are raised in wooden hutches with 1.23 $\mathrm{m}^{2}$ of free space that house 3 calves individually. Producers claim that calves in hutch systems are not ready to wean and be placed in groups at the country-average age of 6 wk. Calves may remain in this individual housing system until as late as $10 \mathrm{wk}$ of age. The objective of this study was to modify space allowance of hutches and evaluate weaning readiness using age at solid feed consumption, standing behaviors, and measures of immunity. Calves were randomly assigned at $4 \mathrm{~d}$ of age to conventional (CONV; $1.23 \mathrm{~m}^{2}$ of space; $\left.\mathrm{n}=18\right)$, moderate (MOD; $1.85 \mathrm{~m}^{2}$ of space; $\mathrm{n}=17$ ), or maximized (MAX; $3.71 \mathrm{~m}^{2}$ of space; $\mathrm{n}=19$ ) space allowance in hutches. These modifications also changed the number of calves housed per hutch from 3 (CONV) to 2 (MOD) and 1 (MAX). Calves were fed milk replacer via bottle twice daily until weaning and offered ad libitum feed throughout the experiment. Step-down weaning was initiated (Wi) at age 53 or $54 \mathrm{~d}$ by withdrawal of the p.m. bottle and was completed (Wc) $11 \mathrm{~d}$ later by removal of the a.m. milk replacer. Accelerometer data for standing behaviors were collected relative to $\mathrm{Wi}$ ( 3 consecutive days to represent $-4 \mathrm{wk},-3 \mathrm{~d}, 3 \mathrm{~d}$, and 3 and $5 \mathrm{wk}$ ). Blood samples were collected in the a.m. just before Wi (d 0) and at d 3, 11, 14, and 18 after Wi. Calves provided with more space (MOD and MAX) compared with CONV calves consumed feed at an earlier age and had slightly healthier erythrocytes, greater circulating glucose, and fewer circulating eosinophils. The CONV calves had haptoglobin (Hp) responses to the stressors

Received July 11, 2018.

Accepted January 19, 2019.

*Present address: Department of Animal Sciences and Industry, Kansas State University, Manhattan 66506.

$\dagger$ Present address: Elanco Animal Health, 2500 Innovation Way, Greenfield, IN 46140.

$\ddagger$ Corresponding author: fmmitloehner@ucdavis.edu of both Wi and Wc and had more IFN- $\gamma$ from whole blood stimulated with phytohemagglutinin-P. The MAX calves had the least active neutrophils (phagocytosis and oxidative burst), but MOD calves' leukocytes secreted the most TNF- $\alpha$ from whole blood stimulated with lipopolysaccharide. Just before and after weaning, MAX calves spent more time per day in the standing position than CONV and MOD calves and had an Hp response to Wc, but MOD calves did not have an $\mathrm{Hp}$ response to $\mathrm{Wi}$ or Wc. Based on these results, MOD calves were the most ready for weaning; therefore, they potentially can be moved to group housing at an earlier age than CONV calves, thus improving animal welfare concerns over space allowance and individual housing. Key words: bovine, immune, stress

\section{INTRODUCTION}

Conventional (CONV) wooden hutch systems are widely adopted by calf raising specialists (CRS) of the southwestern regions of the United States because producers construct hutches in house using low-cost, available, and replaceable materials (Moore et al., 2012; Burciaga-Robles, 2015; Hulbert and Moisá, 2016). These production systems differ from veal production because either they outsource heifer raising for dairies or they buy dairy bull calves from dairy producers to enter beef production (Wolf, 2003; Schaefer, 2005; Burciaga-Robles, 2015). These calves are bottle fed milk or milk replacer and are offered solid feed at 50 to $90 \mathrm{~d}$ of age; then, they are completely weaned from liquid nutrition before they are placed into groups. The space allowance of CONV wooden hutches appears to be limited by the availability of $2.44-\mathrm{m}$ wooden panels, and CONV hutches were originally constructed to maximize the number of calves per hutch to 3. Space allowance for individually housed calves was originally limited by the economic and space constraints within barns and land (Moore et al., 2007; Kertz et al., 2017). However, widespread distribution of pictures revealing poor veal calf housing conditions led to public concern 
over animal welfare, with the restricted space allowance as a top concern (Moore et al., 2007).

Weaning is a potential stressor, and many producers prefer to wait until the calf is sustaining BW from solid feed intake before moving calves out of hutches and into group pens. Dairy producers and CRS often use step-down weaning, which was intended to help the calf become more motivated to consume the readily available solid feed (Walker et al., 2012). Typically, weaning is initiated by reducing volume or solids in a process or 2 or more steps (Hulbert and Moisá, 2016; Kertz et al., 2017). Many CRS use twice-daily bottle feeding, so they simply withdraw 1 feeding or during complete weaning remove the last bottle when they consume enough feed to maintain BW. Although the US average of weaned dairy calves is $6 \mathrm{wk}$, many CRS finish the weaning process as late as 12 wk of age; CRS report that if calves are slow to eat solid feed before weaning and group housing, they are less resilient to respiratory infections (Moore et al., 2007; Hulbert and Moisá, 2016; Love et al., 2016).

We speculated that the space allowance of the CONV hutch may decrease the calf's motivation to stand up and eat calf starter before and during weaning. Although the effects of increasing space allowance on calf solid feed intake and behaviors are varied in other housing systems (Fisher et al., 1985; Friend et al., 1985; Terosky et al., 1997), conventional space allowance was associated with reduced comfort and locomotor play as well as increased fearfulness and stereotypic behaviors in calves (Wilson et al., 1999; Jensen and Kyhn, 2000; Tapkı et al., 2006). To our knowledge, very limited data have been reported on calf lying duration, performance, and health responses to increased space allowance in conventional wooden hutches (Macaulay et al., 1995).

Solid feed consumption is well known to help ruminal and intestinal physical and microbiome development (Anderson et al., 1987; Meale et al., 2016; Kertz et al., 2017). Calves that consume solid feed early in life established an important coping behavior to deal with the potential stressors of bottle removal at weaning and reduced cross-suckling at commingling (Horvath and Miller-Cushon, 2017; Horvath and Cushon, 2017). In addition, early life nutritive and nonnutritive oral behavior development influences immune resilience to stressors (Hulbert et al., 2011; Hulbert and Ballou, 2012; Hulbert and Moisá, 2016).

Therefore, CONV hutches were modified to increase space to $1.85 \mathrm{~m}^{2}$ (MOD) and $3.71 \mathrm{~m}^{2}$ (MAX; CalvoLorenzo et al., 2016, 2017). Both of these modified wooden hutches potentially allow the calf to turn around freely until they were weaned and placed into group pens (i.e., commingling). We hypothesized that space allowance influenced the calves' ability to be ready for weaning and have immune resilience to the stress of weaning. Specifically, the objectives of this study were to determine the influence of wooden hutch space allowance on the duration and frequency of standing, age at consuming a significant amount of calf starter, hematological measures, and ex vivo immune measures.

\section{MATERIALS AND METHODS}

\section{Animal and Housing Treatments}

The experiment was conducted from April to June 2011 at the University of California (UC), Davis, Department of Animal Science's Feedlot and Environmental Research Facility located in Davis, California. Calves were housed and managed from ages $4 \mathrm{~d}$ to 12 wk in accordance with Guide for the Care and Use of Agriculture Animals in Research and Teaching (FASS, 1999). All procedures were approved by the UC Davis Institutional Animal Care and Use Committee (protocol no. 16279). This article is a portion of a larger study that evaluated calf performance and digestive and respiratory health from 0 to $12 \mathrm{wk}$ of age; those data were reported elsewhere (Calvo-Lorenzo et al., 2016, 2017).

Before the start of this study, a total of $60(n=20 /$ treatment) Holstein bull calves were randomly selected at $4 \mathrm{~d}$ of age from a cohort of 120 colostrum-fed calves (total \pm SD plasma protein at age $4 \mathrm{~d}=5.6 \pm 1.1 \mathrm{~g} /$ dL; measured via Rhino Clinical hand-held VET 360 refractometer, Reichert Technologies, Depew, NY). The 120-calf cohort was purchased from a commercial calf ranch in Tulare, California, which selected these calves from 2 commercial dairies ( $>10,000$ cows). After calves were bottle trained, they were transported 365 $\mathrm{km}$ at age $4 \mathrm{~d}$ to the UC Davis Department of Animal Science Feedlot and Environmental Research Facility. Hutches were made of solid wooden panels $(2.44 \times 1.52$ $\times 1.37 \mathrm{~m}$ ) elevated $0.2 \mathrm{~m}$ above a dirt floor and had 0.06-m-wide wooden slatted flooring with $0.03-\mathrm{m}$ gaps positioned across the width of the hutch. The CONV hutches had 2 interbarriers that separated 3 calves within each structure $\left(1.23 \mathrm{~m}^{2}\right.$ of space per calf; Figure 1). Calves were able to make nose-to-nose contact between the top 2 interbarriers through the front bucket access windows. Within a CONV hutch, a bottle holder was centered for each of 3 calves and 2 buckets (water and starter) were placed outside the hutch (Figure 1). Each hutch was placed $0.9 \mathrm{~m}$ apart so that only 3 calves could make contact with each other in this system. The MOD hutches were modified to increase space allowance by placing only 1 interbarrier in the center of a conventional hutch, which housed 2 calves individually with $1.85 \mathrm{~m}^{2}$ of space per calf (Figure 1). This changed the hutch system to 2 bottle holders, neighboring buck- 
ets were spaced father apart, and 2 calves could make nose-to-nose contact with each other. For the MAX hutch, both interbarriers were removed, providing 1 calf $3.71 \mathrm{~m}^{2}$ of space (Figure 1). This changed the hutch system to 1 bottle holder and 1 set of buckets, and calves could not make nose-to-nose contact with each other. Hutches of the same type were arranged next to each other and 3 rows of each treatment were placed in 4 indoor enclosures (Figure 1 in Calvo-Lorenzo et al., 2016). On the day of arrival, calves were randomly assigned to hutch treatments.

\section{Calf Surface Area in Relation to Space Allowance}

Although performance data have been previously reported (Calvo-Lorenzo et al., 2016), it was important for the current article to consider the surface area of the calves in relation to the size of the hutch because as calves increased in BW, the housing space allowance decreased. Therefore, housing space allowances, as a percentage of calf surface area, were calculated from BW collected at d 45 (preweaning) and 73 (postweaning) of age (Calvo-Lorenzo et al., 2016) using equations adapted from Berman (2003) and Hurnik and Lewis (1991). The equation was $\left(0.14 \times \mathrm{BW}^{0.57}\right) /$ housing space allowance $\times 100$.

\section{Feeding and Weaning Methods}

The Institutional Animal Care and Use Committee-approved feeding strategies used in this experiment followed calf-raising specialist standard feeding protocols, which were important to address industry needs pertaining to space allowance and castration. The feeding regimen for healthy calves included milk replacer (Table 1) twice daily (0600 and $1500 \mathrm{~h}$ ), ad libitum feed (Table 1) and water, and, if needed, an additional 2 L of electrolytes (BlueLite C, TechMix LLC, Stewart, MN). All calves were examined daily for clinical signs of sickness, and calves that appeared dehydrated or sick were treated by the collaborating veterinarian. Upon calf arrival to the UC Davis research facility, the collaborating veterinarian determined that all calves had diarrhea and were dehydrated. Therefore, all calves had the milk replacer feeding reduced to the $0600 \mathrm{~h}$ feeding and were provided with 2 to $4 \mathrm{~L}$ of electrolytes in the a.m. and p.m. until d 3 of the trial.

Each morning, solid feed was added if the calf consumed more than $75 \%$ of the previous offering. The quantity of feed offered to each calf was recorded daily. To help determine weaning readiness, the last age (days) at which calves consumed $>250,>750$, $>1,000$, and $>1,600 \mathrm{~g}$ of feed for 3 consecutive days was measured and analyzed for this portion of the
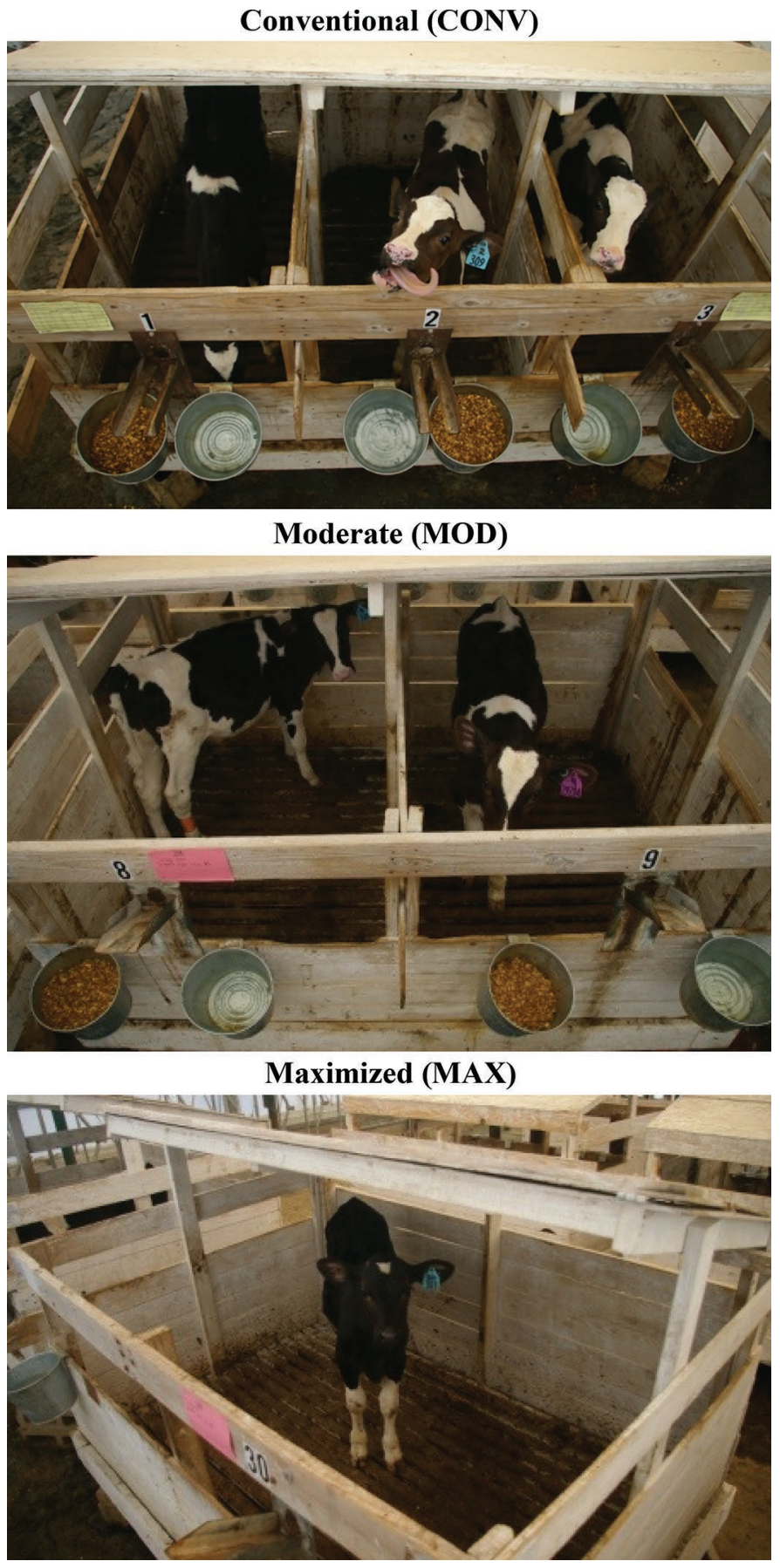

Figure 1. Hutches were made of solid wooden panels $(2.44 \times 1.52$ $\times 1.37 \mathrm{~m}$ ) elevated $0.2 \mathrm{~m}$ above a dirt floor and had $0.06-\mathrm{m}$-wide wooden slatted flooring with $0.03-\mathrm{m}$ gaps positioned across the width of the hutch. The conventional (CONV) hutches had 2 interbarriers that separated 3 calves within each structure $\left(1.23 \mathrm{~m}^{2}\right.$ of space per calf). The moderate (MOD) hutches were modified to increase space allowance by placing only 1 interbarrier in the center of a conventional hutch, which housed 2 calves individually with $1.85 \mathrm{~m}^{2}$ of space per calf. For the maximized (MAX) hutch, both interbarriers were removed, providing 1 calf $3.71 \mathrm{~m}^{2}$ of space. 
Table 1. Formulated nutrient content (as-fed basis) of the milk replacer and dry calf feed fed to calves

\begin{tabular}{|c|c|c|c|}
\hline \multirow[b]{2}{*}{ Item } & \multirow[b]{2}{*}{ Milk replacer ${ }^{1}$} & \multicolumn{2}{|c|}{ Feed $^{2}$} \\
\hline & & Starter & Grower \\
\hline Age fed, wk & 0 to 9 & 0 to 9 & 9 to 12 \\
\hline DM, \% & 97 & 92 & 92 \\
\hline Ether extract (minimum), \% & 20 & 4.8 & 3.9 \\
\hline $\mathrm{CP}$ (minimum), \% & 20 & 18 & 17.5 \\
\hline Crude fiber (maximum), \% & 0.15 & 5.8 & 12.8 \\
\hline Calcium (maximum), \% & 0.75 & 0.8 & 0.9 \\
\hline Calcium (minimum) & 0.6 & 0.6 & 0.7 \\
\hline Phosphorus, \% & 0.5 & 0.3 & 0.25 \\
\hline Vitamin A (minimum), IU/kg & 46,297 & 26,455 & 20,944 \\
\hline Vitamin $\mathrm{D}_{3}$ (minimum), IU $/ \mathrm{kg}$ & 9,259 & - & - \\
\hline Vitamin E (minimum), IU/kg & 661 & - & - \\
\hline Monensin Na, \% & - & 0.441 & 0.441 \\
\hline
\end{tabular}

${ }^{1}$ Calves were bottle fed a commercial milk replacer (Veal Tech Inc., Oswego, IL) at $1.2 \%$ of calf BW (259 g/2 $\mathrm{L}$ of water) twice daily at 0600 and $1500 \mathrm{~h}$ until step-down weaning that was initiated at 52 and $53 \mathrm{~d}$ of age (p.m. milk replacer removed) and completed $11 \mathrm{~d}$ later (a.m. milk replacer removed). Milk replacer comprised dried whey protein concentrate, dried whey, dried skim milk, proprietary blend of milk and vegetable fats with coconut oil (butylated hydroxytoluene) and citric acid added, lecithin, calcium carbonate, L-lysine, DLmethionine, threonine, inulin (fructooligosaccharide), yeast autolysate dehydrate (mannan-oligosaccharide), dicalcium phosphate, vitamin $\mathrm{A}$ acetate, vitamin $\mathrm{D}_{3}$ (cholecalciferol), vitamin $\mathrm{E}$ (D- $\alpha$ tocopherol acetate), vitamin $\mathrm{K}$ (menadione sodium bisulfate complex), vitamin $\mathrm{B}_{12}$ supplement, ethylenediamine dihydroiodide, thiamine mononitrate, niacin supplement, riboflavin, pyridoxine $\mathrm{HCl}$, Ca pantothenate, D-biotin, ascorbic acid, folic acid, $\mathrm{Mg}$ sulfate, $\mathrm{Cu}$ proteinate, $\mathrm{Cu}$ sulfate, $\mathrm{Zn}$ proteinate, $\mathrm{Zn}$ sulfate, Co sulfate, Na molybdate, $\mathrm{Na}$ selenite, and mono- and diglycerides.

${ }^{2}$ Calves were fed ad libitum 2 commercial calf feeds (Best StartTM, 5506 ALG calf starter mix [2010-18]-M and 5518 ALG heifer grower mix [2010-15]-M; A.L. Gilbert Co., Oakdale, CA) that provided similar macroingredients, which included grain products, processed grain by-products, plant and milk protein products, animal and plant fat products, molasses and roughage products with trace minerals, and a proprietary blend of yeast product.

study. The step-down weaning approach required that all calves consume between 750 and $1,000 \mathrm{~g}$ of feed for 3 consecutive days before weaning could be initiated, which occurred for all calves by the end of age $7 \mathrm{wk}$. A step-down weaning protocol was used. To logistically process samples, weaning was initiated $\left(\mathbf{W}_{\mathbf{i}}\right)$ at age 53 or $54 \mathrm{~d}$ by removal of the p.m. milk replacer feeding (block $\mathrm{A}, \mathrm{n}=9$ /treatment; block $\mathrm{B}, \mathrm{n}=9,8$, and 10 for CONV, MOD, and MAX, respectively). One week after weaning initiation, all calves were consuming at least $1,600 \mathrm{~g}$ of feed; therefore, weaning was completed at age 64 or $65 \mathrm{~d}$ by removal of the a.m. milk replacer bottle.

\section{Standing and Lying Activity Before, During, and After Weaning Initiation}

A total of 16 calves per treatment were randomly selected to wear activity data loggers (64k, Onset Pendant G, Onset Computer Corp., Bourne, MA; previously described in Calvo-Lorenzo et al., 2016). To avoid excessive handling of calves, loggers were replaced only on the days BW were collected, which was at ages 3, 6, 10, and 12 wk. Logger sampling rates (every $30 \mathrm{~s}$ ) allowed for only 10 full 24 -h days of data storage. This limited data set permitted the assessment of average daily stand-lie activities before, during, and after Wi by subsampling three 24 -h periods. The subsamples included the last $3 \mathrm{~d}$ of age $4 \mathrm{wk}$, the $3 \mathrm{~d}$ before and after $\mathrm{W}_{\mathrm{i}}$, and the last $3 \mathrm{~d}$ of ages 3 and $5 \mathrm{wk}$. The data were downloaded using Onset HOBOware software (Onset Computer Corp.) and were exported into Microsoft Excel (Microsoft Corp., Redmond, WA) to organize and summarize for statistical analyses as described previously (Ledgerwood et al., 2010; Bonk et al., 2013) in SAS (version 9.2, SAS Institute Inc., Cary, NC).

\section{Blood Sampling and Hematology Analyses}

Nine milliliters (3-mL EDTA and 6-mL heparinized evacuated containers) of peripheral blood was collected via jugular venipuncture. Samples were collected at $0600 \mathrm{~h}$ before adding feed or milk replacer feedings just before $\mathrm{W}_{\mathrm{i}}$, and $3 \mathrm{~d}$ after $\mathrm{W}_{\mathrm{i}}$. In addition, blood samples were collected at 11,14 , and 18 d relative to $\mathrm{W}_{\mathrm{i}}$. Within $1 \mathrm{~h}$ after collection, the 3-mL EDTA evacuated container from each calf was analyzed for hematology using a Procyte blood analyzer (Idexx Laboratories, Sacramento, CA). In addition, the neutrophil:lymphocyte cell ratio was calculated. 


\section{Plasma Collection and Analyses}

Plasma from the 6-mL heparin tube was collected after centrifugation at $1,250 \times \mathrm{g}$ for $20 \mathrm{~min}$ at $4^{\circ} \mathrm{C}$ and stored at $-20^{\circ} \mathrm{C}$ until analysis. Cortisol concentrations were measured by ELISA using a commercially available kit (Arbor Assays, Ann Arbor, MI), and the intra- and interassay variations were 6.5 and $7.8 \%$, respectively. Plasma glucose, urea nitrogen, haptoglobin, and zinc concentrations were measured as described previously (Ballou et al., 2011). The intra-assay variations were $2.9,5.8,5.9$, and $2 \%$ for glucose, urea nitrogen, haptoglobin, and zinc concentrations, respectively. The interassay variations were 4.5, 6.1, 8.3, and $1.8 \%$ for glucose, urea nitrogen, haptoglobin, and zinc concentrations, respectively.

\section{Whole-Blood Culture Analyses}

Measures of ex vivo inflammatory regulation were performed by first stimulating whole blood with either LPS (Escherichia coli O111:B4; 1 $\mu \mathrm{g} / \mathrm{mL}$; Sigma-Aldrich, St. Louis, MO) or phytohemagglutinin-P (PHA; $25 \mu \mathrm{g} / \mathrm{mL}$; L 8754; Sigma-Aldrich) for 24 or $72 \mathrm{~h}$, respectively (previously described by Calvo-Lorenzo et al., 2017). Then, cytokine secretion of bovine-specific TNF- $\alpha$ or IFN- $\gamma$ was measured in the supernatant fraction of the LPS- or PHA-treated samples, respectively, using commercially available ELISA kits (KingFisher Biotech, St. Paul, MN). Standards were diluted in RPMI medium with $10 \%$ pooled bovine plasma and $1 \%$ antibiotics (Gibco Antibiotic-Antimycotic, Invitrogen, Carlsbad, CA). The TNF- $\alpha$ intra- and interassay coefficients of variation were 8.4 and $3.8 \%$, respectively, and sensitivity of the assay was $78.1 \mathrm{pg} / \mathrm{mL}$. The IFN$\gamma$ intra- and interassay coefficients of variation were 8.5 and $3.3 \%$, respectively, and sensitivity of the assay was $93.8 \mathrm{pg} / \mathrm{mL}$. A bactericidal activity test against live $E$. coli was performed on heparinized whole blood (whole-blood anti-E. coli; described previously in Calvo-Lorenzo et al., 2017). Briefly, blood was diluted (1:2) with RPMI 1640, which produced a final concentration of 2,000 cfu of E. coli 8739 (Microbiologics, St. Cloud, MN) per milliliter. Quality control and standard samples had RPMI only with a final concentration of 0 and 2,000 cfu, respectively. Quality control and standard samples were created for every batch of 10 whole-blood samples. Samples were placed in a $38.5^{\circ} \mathrm{C}$ circulating water bath for $10 \mathrm{~min}$. Then, $50 \mu \mathrm{L}$ was cultured on duplicate tryptic soy agar Petri dishes for $24 \mathrm{~h}$ in a humidified $5 \% \mathrm{CO}_{2}$ chamber at $38.5^{\circ} \mathrm{C}$. All plate colony-forming units were manually counted, and percentage bactericide for each unknown sample was calculated using the accompanying standard.
From whole blood (heparin), neutrophil inflammatory responses were measured using the simultaneous phagocytic and oxidative burst capacities of peripheral blood neutrophils in response to heat-killed $E$. coli and were analyzed as previously described by Calvo-Lorenzo et al. (2017). Briefly, heat-killed E. coli were labeled with propidium iodide and stored at $10^{9}$ $\mathrm{cfu} / \mathrm{mL}$ in $1 \times \mathrm{PBS}$ at $-80^{\circ} \mathrm{C}$. Two hundred microliters of whole blood (sodium-heparin) from the $6-\mathrm{mL}$ evacuated tube per animal was incubated in an ice bath for $5 \mathrm{~min}$. Forty microliters of a $100 \mu M$ working concentration of dihydrorhodamine (Invitrogen) and the fluorescently labeled $E$. coli were added to each sample, vortexed thoroughly, and then incubated in a $38.5^{\circ} \mathrm{C}$ water bath for $10 \mathrm{~min}$. After completion of incubation, the samples were immediately placed in an ice bath for $5 \mathrm{~min}$. Erythrocytes were hypotonically lysed with ultrapurified deionized $\mathrm{H}_{2} \mathrm{O}$ and washed, and the leukocytes were analyzed by dual-color flow cytometery (FACScan Flow Cytometer, Becton Dickinson, Fullerton, CA). Using flow cytometer analysis software (Flowjo 7.6.3, Treestar Inc., Ashland, OR), neutrophils were gated on the scatter plot of electric volume $\times$ side scatter. Neutrophils that were positive for both oxidative burst $(\mathbf{O B}+)$ and phagocytosis $(\mathbf{P G}+)$ were then gated using the FL-1 by FL-3 scatter plot. The $\mathrm{OB}+\mathrm{PG}+$ cell percentage and geometric mean fluorescence intensity of the FL-1 and FL-3 were analyzed for oxidative burst and phagocytosis, respectively.

\section{Statistical Analyses}

A linear mixed model with the fixed effects of time, treatment, and the interactions of treatment $\times$ time and block (weaning group) $\times$ treatment $\times$ time was fitted. The random effect was calf nested within treatment $x$ block. All data were analyzed by restricted maximum likelihood ANOVA using the MIXED procedure of SAS (version 9.2, SAS Institute Inc.). The anteregressive (1) covariance structure for the within-subject measurement was used for all models. Repeated data were tested for normality of the residuals by evaluating the Shapiro-Wilk statistic using the UNIVARIATE procedure of SAS (version 9.2, SAS Institute Inc.). Data that were not normally distributed were log or arcsine square root transformed before mixed model analysis. Pairwise comparisons were performed (1) among treatments at each time using a sliced-effect multiple comparison approach and (2) within each treatment across time using a Tukey-Kramer adjustment to control the family-wise type-1 error. Least squares means ( \pm standard error of the mean) are reported throughout. Treatment, time, and interaction differences of $P<0.05$ were considered 
significant, and $P>0.05<0.10$ was considered a tendency when biologically appropriate.

\section{RESULTS AND DISCUSSION}

Calf raising specialists have the capability of raising tens of thousands of calves on a single ranch at a fraction of the cost per calf compared with traditional dairies (Wardynski, 2012), and this is partially due to the low-cost wooden hutch system. Therefore, we suggested that modification of current hutches be used as a shortterm solution for calf raisers who want to keep the current weaning strategy and age at weaning but increase space allowance. Given the limitations of the available wooden panel, the current hutch design was modified to increase space allowance by 1.5 to 3 times the amount of space CONV hutches provided. Notably, this space allowance change also changes the number of calves per hutch to 2 and 1 calf, respectively. Therefore, logically, space allowance changes the microenvironment and the housing system due to social contact, bottle holders, and feed and water bucket placement. The objectives were to determine how each space allowance system influenced behavior, stress responses, and measures of immunity before and after weaning.

\section{Calf Growth and Surface Area}

We previously reported that as space allowance increased, BW at ages 6 and 12 wk increased (CalvoLorenzo et al., 2016). By age $3 \mathrm{wk}, 4$ calves died and 1 calf had severe enteric respiratory illness and was not suitable to wean (details in Calvo-Lorenzo et al., 2016). Therefore, this portion of the experiment had housing treatments with $\mathrm{n}=18,17$, and 19 for CONV, MOD, and MAX, respectively. Hurnik and Lewis (1991) suggested that Canadian space allowance be set to $60 \%$ of the calves' surface area (Code of Practice, 1988). For the current article, we hypothesized that only slower growing calves in the CONV and MOD hutches met Hurnik and Lewis' (1991) suggestion just before (6 wk) and after (12 wk) of weaning. We observed that although MOD hutches met the surface area suggestion before weaning (Figure 2; $P<0.05$ ), after weaning MOD hutches were not different from CONV hutches for surface area to free space measures (Figure 2; $P$ $>0.10)$. We noted that variation of individual calf growth was greater among calves in the MOD and MAX hutches (standard deviation reported in Figure 2). Homogenously sized calves may be convenient for grouping during commingling because larger animals tend to impede smaller animals' feed intake (Fiol et al., 2017 ), but natural variation in growth rates and stress responses is important to determine which animals' ge- netics are more suited for stress and immune resilience (Mitra et al., 2009). These data provide evidence that CONV space allowance impedes growth potential of some calves; therefore, the housing system itself may be playing a major role in delaying the weaning and commingling stages.

\section{Behavior}

More recent guidelines in Canadian and US state legislation do not state a specific space allowance; rather, the housing system should allow animals to easily "stand up, lie down, turn around freely, and adopt normal resting postures" (e.g., California Attorney General, 2008; NFACC, 2009). The requirement for the calf to "turn around freely" may be a challenge for CRS who house calves using the CONV system because of the weaning process and timeline. The "turn around freely" requirement is a challenge for CONV-housed calves; as they grow, it becomes more difficult to turn around with ease. We hypothesized that this "ease" to turn around freely would alter calf motivation to be in the standing position and potentially perform active behaviors, such as eating solid feed.

Before weaning (4 wk of age), there were no differences among treatments for stand-lie activities (Figure $3 ; P>0.10)$. We expected this outcome because at 4 wk of age, calf surface area and free space likely did not restrict movement. Calves in the MAX hutches spent more time in the standing position and had longer bouts of standing during the weaning period than both CONV and MOD calves. Interestingly, although CONV and MOD calves were not nearly as active (assuming that standing is an active behavior state) as MAX calves, they had more standing bouts per day than MAX calves (Figure 3; $P<0.05$ ). This is an indicator that CONV and MOD calves were not as motivated to stay in an active state as MAX calves because the shifting between lying and standing may indicate that they were not comfortable (Færevik et al., 2008; Camiloti et al., 2012; Bonk et al., 2013). In addition, CONV calves rested more on their left side, whereas MOD and MAX calves rested more evenly (Table $2 ; P<0.05$ ). Laterality is observed in adult dairy cattle that have apparent discomfort (e.g., cannula, late gestation; Tucker et al., 2009). Researchers suspected that housing system restrictions in movement will increase laterality among adult animals, but results were inconsistent between studies (Haley et al., 2000; Tucker et al., 2009). Nonetheless, the current experiment demonstrated that symmetry in lying increased with increased space allowance. More research is needed to determine whether symmetrical lying is an indicator of comfort among calves. 


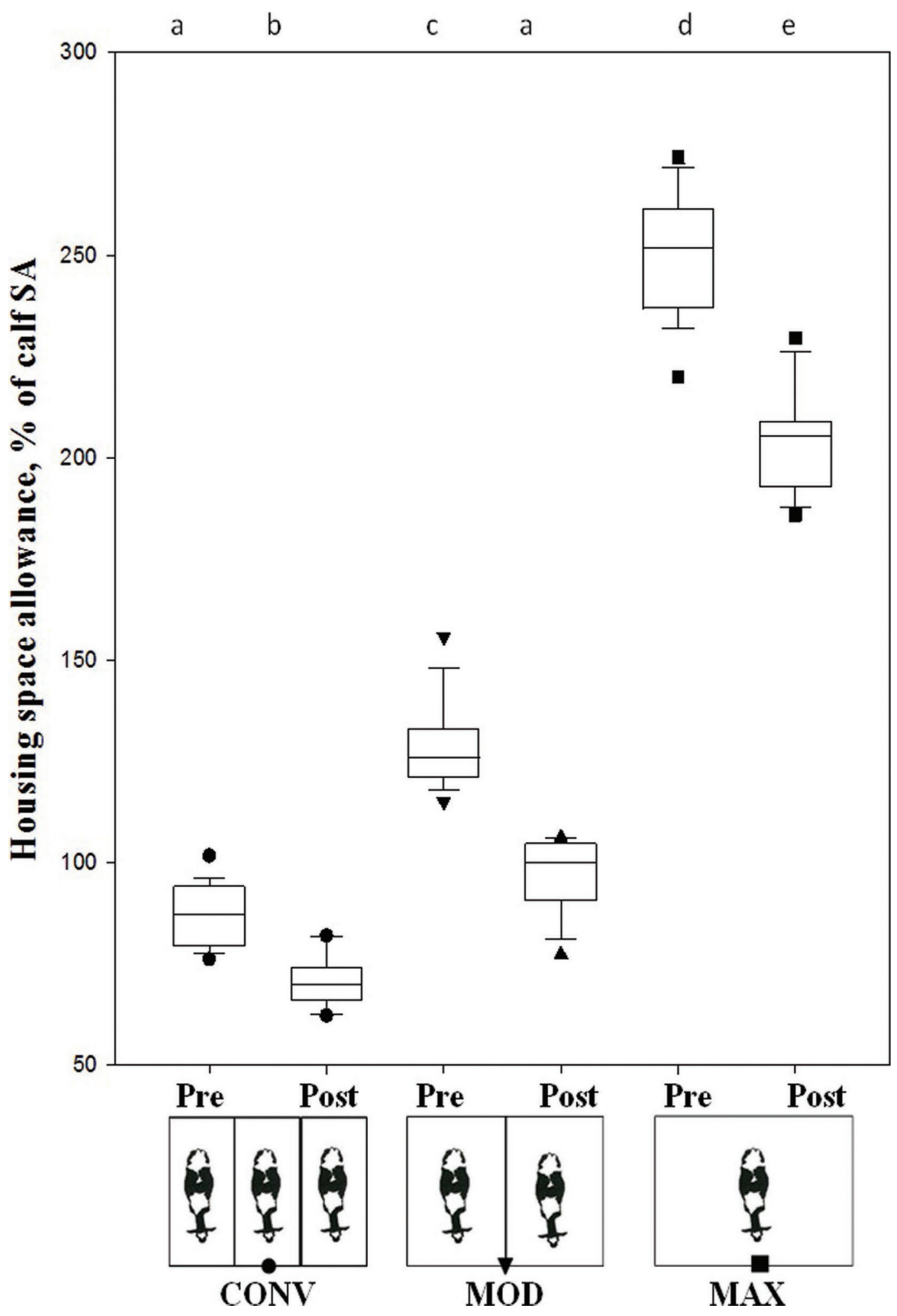

Figure 2. Box plots (center line $=$ mean, error bars $=\mathrm{SD}$, and points = outliers) of preweaning (age $45 \mathrm{~d}$ ) and postweaning (age $73 \mathrm{~d}$ ) space allowance on the percentage of calf surface area [SA; $\left(0.14 \times \mathrm{BW}^{0.57}\right) /$ housing space allowance $\times 100$; Hurnik and Lewis, 1991; Berman, 2003] for calves housed in conventional (CONV; $\left.1.23 \mathrm{~m}^{2} ; \mathrm{n}=18\right)$, moderate (MOD; $1.85 \mathrm{~m}^{2} ; \mathrm{n}=17$ ), or maximized (MAX; $\left.3.71 \mathrm{~m}^{2} ; \mathrm{n}=19\right)$ hutches after weaning. Weaning was initiated at age 53 or $54 \mathrm{~d}$ by removal of the p.m. milk replacer bottle and was completed $11 \mathrm{~d}$ later by removal of the a.m. milk bottle. $P$-values for treatment, time, and treatment $\times$ time were $<0.01$. Least squares means with different letters $(a-e)$ differ $(P$ $<0.01$; Tukey-Kramer adjustment). 
A

B.
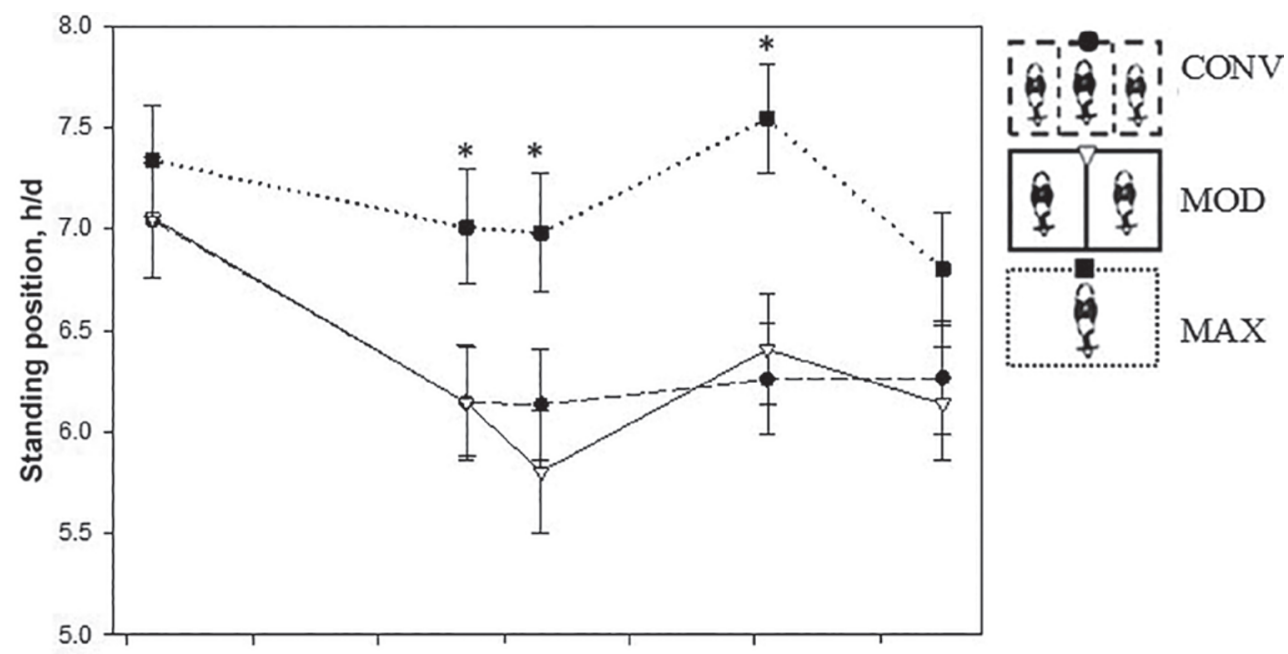

C.
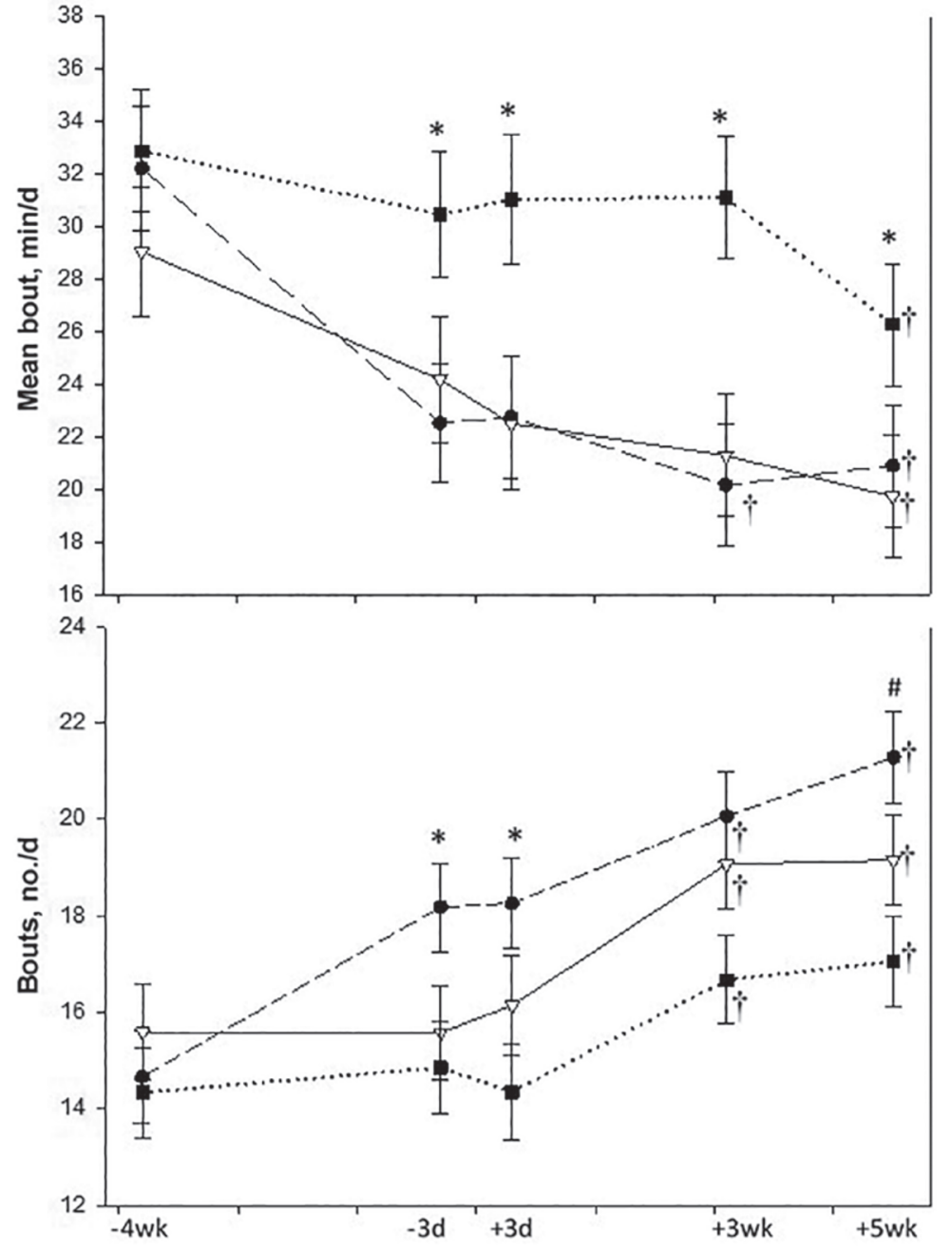

Time relative to initiation of weaning

Figure 3. The daily means and SE for (A) total standing position, (B) standing bout duration, and (C) number of standing bouts among calves housed in wooden hutches with conventional (CONV; $\left.1.23 \mathrm{~m}^{2} ; \mathrm{n}=16\right)$, moderate (MOD; $\left.1.85 \mathrm{~m}^{2} ; \mathrm{n}=16\right)$, or maximized $\left(\mathrm{MAX} ; 3.71 \mathrm{~m}^{2}\right.$; $\mathrm{n}=16)$ space allowance after weaning. Weening was initiated at 53 or $54 \mathrm{~d}$ of age by removal of the p.m. milk replacer bottle and completed $11 \mathrm{~d}$ later by removal of the a.m. milk bottle. Behaviors were sampled from 72 -h periods relative to initiation. *Means across treatments within a time point differ $(P<0.05)$. $†$ Means within housing treatment are different from $\mathrm{d} 0(P<0.05$; Tukey-Kramer adjustment. \#LSM tended $(P=0.10)$ to differ. 


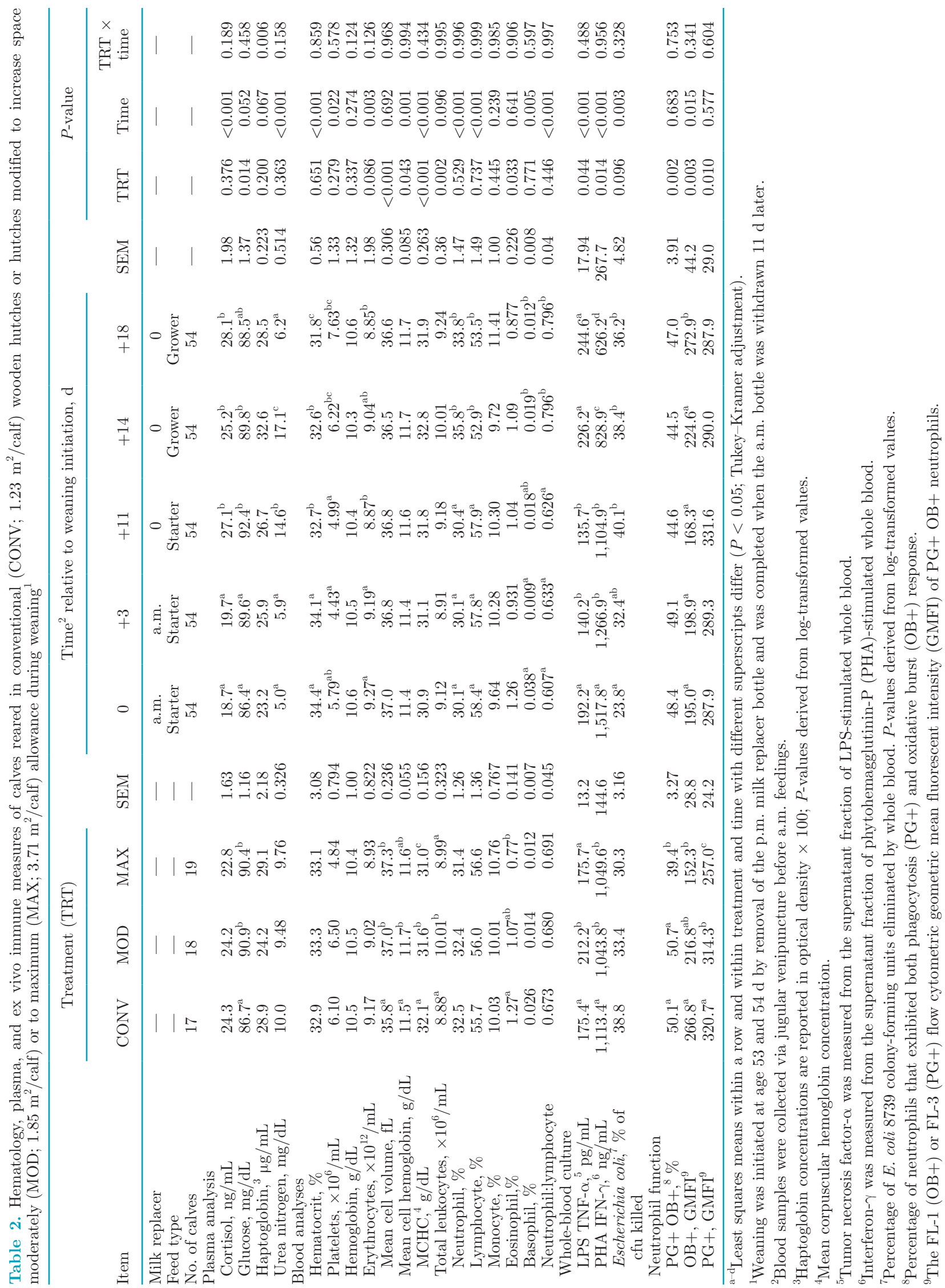




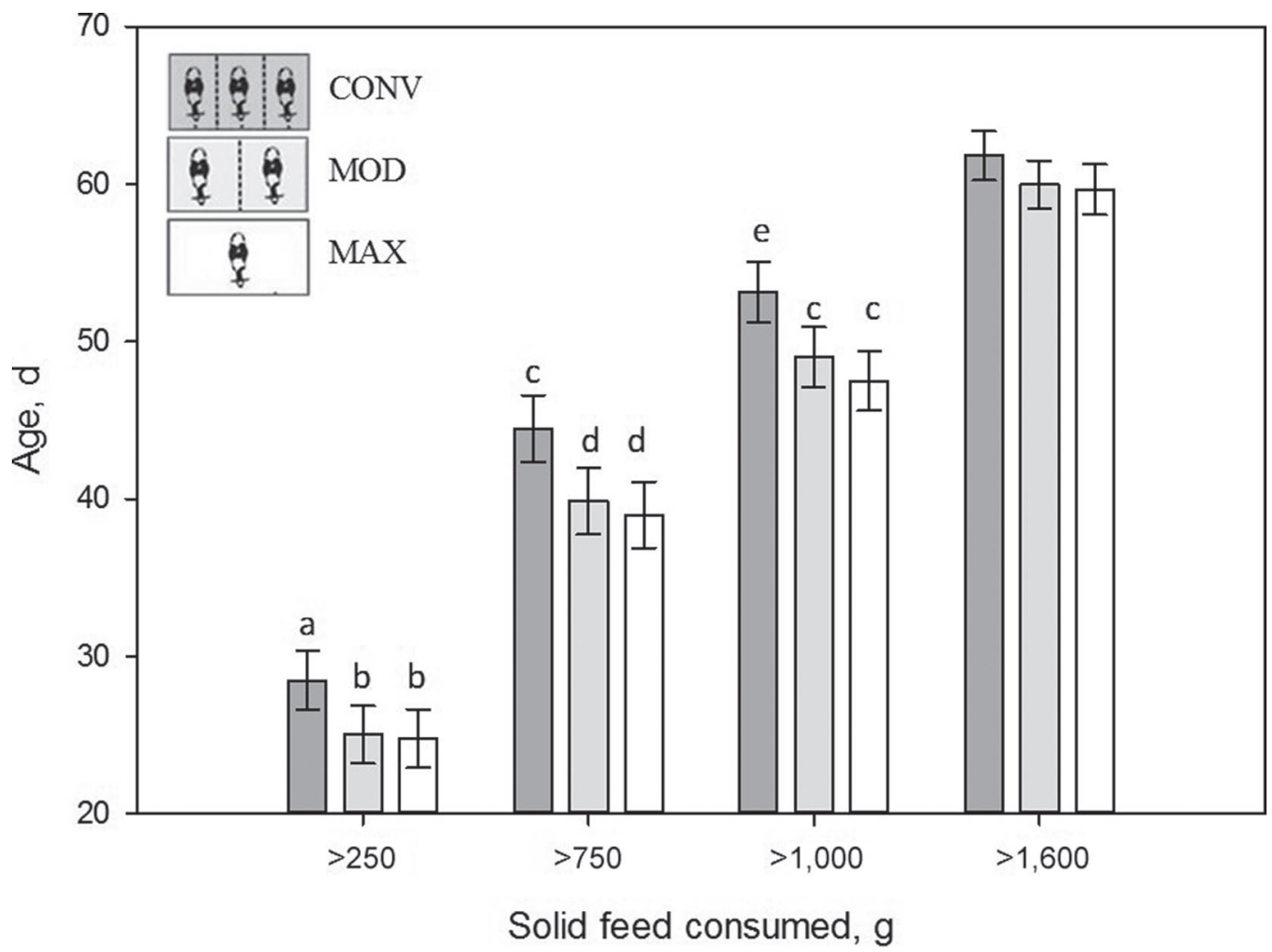

Figure 4. Age when consuming 250, 750,1,000, or 1,600 g of feed for 3 consecutive days among calves housed in wooden hutches that provided conventional (CONV; $1.24 \mathrm{~m}^{2}$ of space/calf; $\left.\mathrm{n}=18\right)$, moderate (MOD; $1.85 \mathrm{~m}^{2}$ of space/calf; $\mathrm{n}=16$ ), or maximized (MAX; $3.71 \mathrm{~m}^{2}$ of space/calf; $n=16$ ) space allowance before and after weaning. Weaing was initiated at age 53 or $54 \mathrm{~d}$ by removal of the p.m. milk replacer bottle and completed $11 \mathrm{~d}$ later by removal of the a.m. milk bottle. $P$-values for treatment, time, and treatment $\times$ time were $<0.05$. Least squares means with different letters (a-e) differ $(P<0.01$; Tukey-Kramer adjustment). Error bars represent SEM.

\section{Solid Feed Intake}

Calves may show that they are less neophobic about their environment and new substrates by exploring more while they are in the standing position and discovering the available highly palatable solid feed (Fujiwara et al., 2014). Although total feed consumption did not differ among treatments (Calvo-Lorenzo et al., 2016), MAX and MOD calves displayed that they were more ready for weaning than CONV calves by consuming set amounts of feed $(250,750$, and 1,000 g) at earlier ages than CONV calves (Figure 4; $P<0.05$ ). Interestingly, once weaning was initiated, there were no differences $(P>0.10)$ in the age at which calves consumed $>1,600$ $\mathrm{g}$ of feed, nor were there differences among treatments for total feed consumed during the weaning period (age 6-10 wk; Calvo-Lorenzo et al., 2016). Not only are the active behaviors of exploratory and play behavior important for coping with normal, inevitable stressors (Rushen and de Passillé, 2014), early life consumption of solid feed contributes to the development of the ruminal and fecal microbiomes (Anderson et al., 1987;
Meale et al., 2016). Early life seeking of solid feed is an important behavior for calves to be more resilient to the potential stress of weaning (Hulbert and Moisá, 2016).

In addition to taking longer to start consuming feed, CONV calves had the lowest glucose concentration (Table 2; $P<0.05$ ). Blood samples were collected early in the morning $(0600 \mathrm{~h})$ before routine bottle feeding and adding feed and water to buckets. Foote et al. (2007) reported that blood glucose concentrations were lower in calves with slow growth rates $(0.55 \mathrm{~kg} / \mathrm{d}$ growth rates) than calves with fast growth rates (1.2 $\mathrm{kg} / \mathrm{d}$ ). We previously reported that CONV calves had slower growth rates at ages 1 to 4 wk compared with MOD and MAX calves (Calvo-Lorenzo et al., 2016). Therefore, observations of lower glucose concentrations combined with the older age to consume feed are indicators that CONV calves were less likely to be ready for weaning than calves in the other treatments.

We noted that behavior and subsequently, immune function, are also influenced by nutrition. In the current experiment, calves were fed in 2011, when con- 
ventional composition of milk replacer was formulated for much slower growth rates than formulations with moderate to higher planes of nutrition (Dennis et al., 2018a,b; Sharon et al., 2019). The past formulation of milk replacer motivated calves to seek out solid feed more than calves on higher planes of nutrition (Sharon et al., 2019). For the current experiment, CONV calves were the slowest to start eating significant amounts of solid feed. As CRS adopt feeding methods with higher planes of nutrition, we speculate from this experiment that MOD- and MAX-housed calves will be more likely to continue to eat solid feed at early ages than CONV calves.

\section{Measures of Stress and Immune Resilience}

There were no treatment differences in cortisol concentration and neutrophil:lymphocyte ratio (Table 2; $P>0.05)$. Researchers often use these measures to determine whether the animal experienced acute stress, as cortisol is secreted from adrenals within 5 to $30 \mathrm{~min}$ after an acute stressor (Lefcourt and Elsasser, 1995; Hulbert et al., 2013), and the acute stressor can cause shifts in neutrophil:lymphocyte ratio (increased) for up to $3 \mathrm{~d}$ after a stressor, such as transportation or weaning (Arthington et al., 2003; Hulbert et al., 2011). For this experiment, sample collection was established to determine whether the chronic stress of limited space allowance would impede the normal cortisol secretion caused by the housing system, an indicator of adrenal fatigue, and thus influence the influx of circulating neutrophils. For example, Friesian-Holstein bulls housed at $95 \%$ of surface area had a greater cortisol response to transportation than bulls housed at 62 and $27 \%$, indicating that the animals with less space had adrenal fatigue (Gupta et al., 2007). Nonetheless, for the current experiment, all calves had comparable cortisol concentrations that are similar to literature findings of calves during weaning (Hickey et al., 2003; Kim et al., 2011; Abdelfattah et al., 2018), and all calves experienced increased cortisol secretion after weaning was finalized (Table 2 ; time $P<0.05$ ).

Although haptoglobin is an acute phase protein typically associated at high peripheral concentrations with immune challenges and diseases such as bovine respiratory disease (Heegaard et al., 2000; Hulbert et al., 2013; Moisá et al., 2018), in healthy cattle, the liver releases haptoglobin 24 to $72 \mathrm{~h}$ after an acute stress stimulus such as transportation (Murata and Miyamoto, 1993; Hulbert et al., 2011), abrupt weaning (Hickey et al., 2003), first commingling (Arthington et al., 2003), or a corticotropin-releasing hormone challenge (Hulbert et al., 2011). The philosophy behind step-down weaning is to ease the calves into their new solid feed diet so that by the time the second bottle is removed, they are less stressed because they are coping by consuming feed (Kertz et al., 2017). However, calves in the current experiment were already consuming a large amount of solid feed before weaning, but it appeared that these calves were still motivated for milk consumption after that last bottle was removed. Calves housed in CONV hutches had a haptoglobin response to both weaning initiation and completion (Figure 5; $P<0.05$ ). Interestingly, MAX calves' haptoglobin increased from their baseline concentration when weaning was finalized (Figure 5; $P<0.05$ ), but MOD calf haptoglobin responses were not different from their baseline measures. Based on haptoglobin responses to bottle removal, we deduced that step-down weaning was the most appropriate for MOD calves.

Haptoglobin is released in response to stress to help prepare the immune system for potential infection or injury and plays a role in hemoglobin, erythrocyte, and leukocyte profiles (Lynch et al., 2010). For this experiment, all calves had consistently healthy concentrations of hemoglobin and numbers of erythrocytes and leukocytes (Table 3). Space allowance appeared to slightly (Table 2; $P<0.05$ ) influence measures of hemoglobin and erythrocyte health. The MOD calves had the greatest mean cell volume, mean cell hemoglobin, and mean corpuscular hemoglobin concentrations (Table $3 ; P<$ $0.05)$. In addition, MOD calves had slightly more circulating leukocytes (Table 3; $P<0.01$ ). Leukocyte numbers among all samples were well within normal ranges, but MOD calves also had the greatest TNF- $\alpha$ secretion after their blood was stimulated with LPS (Table 3; $P=0.044$ ). This ex vivo measure of immunity tests how functional the monocytes and lymphophocytes respond to molecular patterns (microbial-associated molecular patterns; MAMP). Lipopolysaccharide is a MAMP that most species' immune systems respond to strongly with many cytokines; TNF- $\alpha$ is a primary cytokine released in response to LPS. If LPS is in the periphery, the body can overrespond as if the animal were septicemic; therefore, a rapid, regulated response is less risky for the animal than a slow, less regulated response. The ex vivo test with LPS allows us to test the competence of this innate immune response without putting the animal through a state of septicemia (Finch-Arietta and Cochran, 1991; Heagy et al., 2003; Carstensen et al., 2005). We previously reported that the MOD and CONV calves had dirtier hides than the MAX calves during the preweaning period (CalvoLorenzo et al., 2016). As previously mentioned, MOD calves also were consuming feed at an earlier age, and they did not appear to have haptoglobin secretion in response to bottle removal. Therefore, we suspect that the combination of early-age consumption of solid feed, 


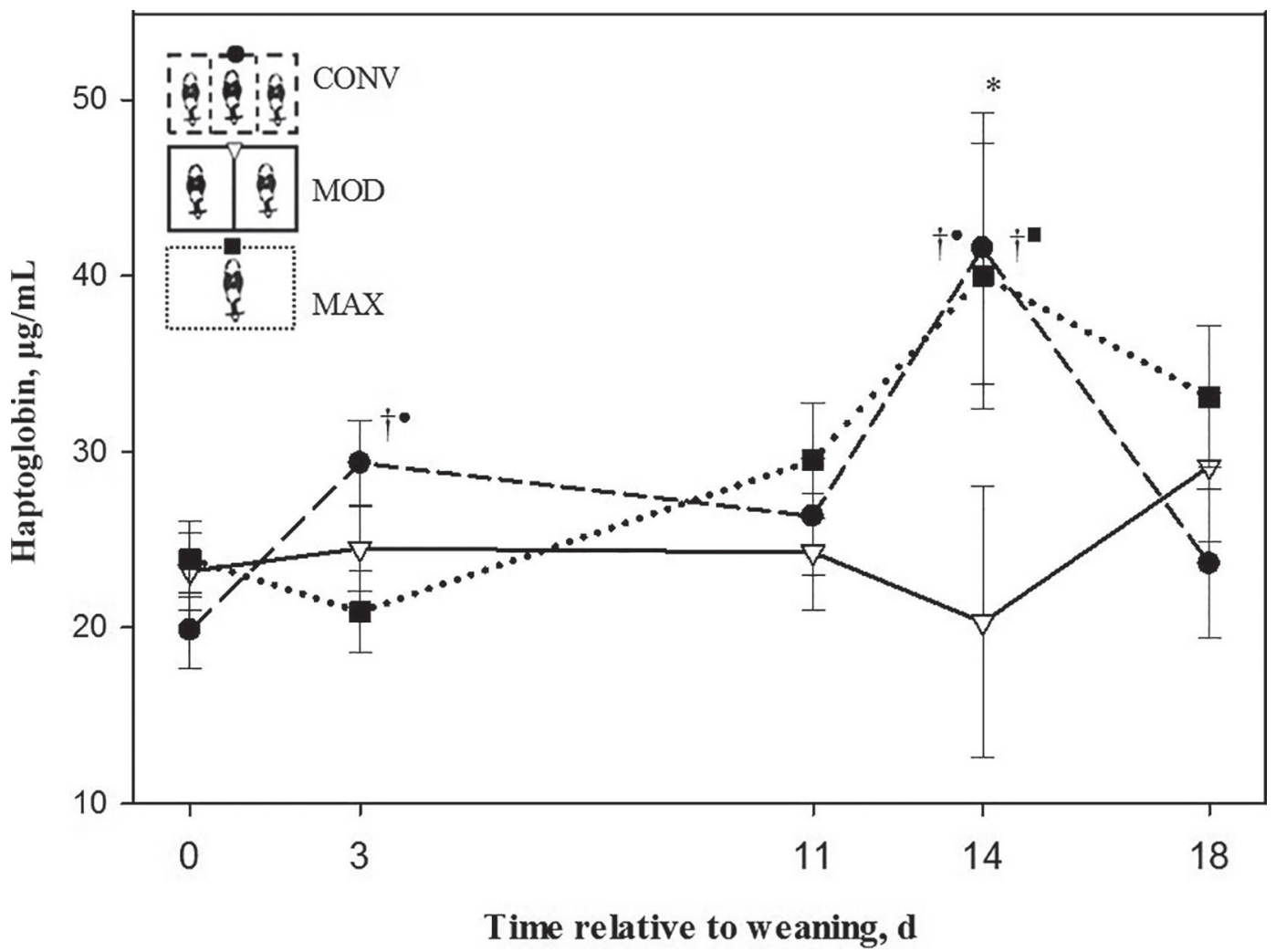

Figure 5. Plasma haptoglobin means and SE among calves housed in wooden hutches that provided conventional $\left(\mathrm{CONV} ; 1.24 \mathrm{~m}^{2}\right.$ of space/ calf; $\mathrm{n}=18$ ), moderate (MOD; $1.85 \mathrm{~m}^{2}$ of space/calf; $\mathrm{n}=16$ ), or maximized (MAX; $3.71 \mathrm{~m}^{2}$ of space/calf; $\mathrm{n}=16$ ) space allowance before and after weaning. Weaning was initiated at age 53 or $54 \mathrm{~d}$ by removal of the p.m. milk replacer bottle and completed $11 \mathrm{~d}$ later by the removal of the a.m. milk bottle. ${ }^{*}$ Means across treatments within a time point differ $(P<0.05) . \dagger^{\bullet}$ Means within CONV housing treatment are different from d $0(P<0.05$ from root-transformed data and Tukey-Kramer adjustment $)$. $\dagger$ Means within MAX housing treatment are different from $\mathrm{d}$ $-1(P<0.05 ;$ Tukey-Kramer adjustment).

microbial exposure, and less stress during step-down weaning contributed to these measures of immune resilience among MOD calves.

However, CONV calves also had some measures of immunity that differed from MOD and MAX calves. Although leukocyte numbers were within normal ranges, CONV calves had greater percentages of circulating eosinophils than MOD and MAX calves $(P=0.033$; Table 3). Most mammalian species evolved immune responses with eosinophils to ward off pathogens with their cytotoxic effector functions, but paradoxically, eosinophils can also exacerbate respiratory inflammation (Kusnecov and Rossi-George, 2002; Shamri et al., 2011). After weaning, the risk of calves contracting bovine respiratory disease increases (Hulbert and Moisá, 2016); therefore, we suspect that CONV calves may be at greater risk for too much inflammation if they contract bovine respiratory disease. However, experts in the stress immune interactions (Kusnecov and RossiGeorge, 2002; Sorrells and Sapolsky, 2007) conclude that short-term changes in immunity from stressors may not necessarily be maladaptive in the long term; therefore, the current experiment's findings warrant more research specific to space allowance and calf susceptibility to bovine respiratory disease.

Eosinophils also possess a wide range of receptors for MAMP; once activated, they degranulate to provide other leukocytes a milieu of cytokines, chemokines, mediators, and other factors during an innate immune response (Shamri et al., 2011). Therefore, in addition to a greater percentage of eosinophils, CONV calves had the greatest IFN- $\gamma$ from whole blood stimulated with PHA (Table 3; $P=0.014$ ). Phytohemagglutinin used for this ex vivo response is a lectin that is derived from legumes. In ex vivo whole-blood culture, PHA agglutinates with erythrocytes and leukocytes, which secrete IFN- $\gamma$ to induce proliferation. Hickey et al. (2003) reported decreased ex vivo secretion of IFN- $\gamma$ among beef calves that were weaned abruptly rather than through a step-down process; however, in the current experiment, we did not observe treatment $\times$ time differences (Table 2; $P=0.328$ ). Rather, all of the calves had decreased IFN- $\gamma$ from PHA-stimulated whole blood (time $P<0.001$; Table 2) $3 \mathrm{~d}$ after Wi. Calves had even less 


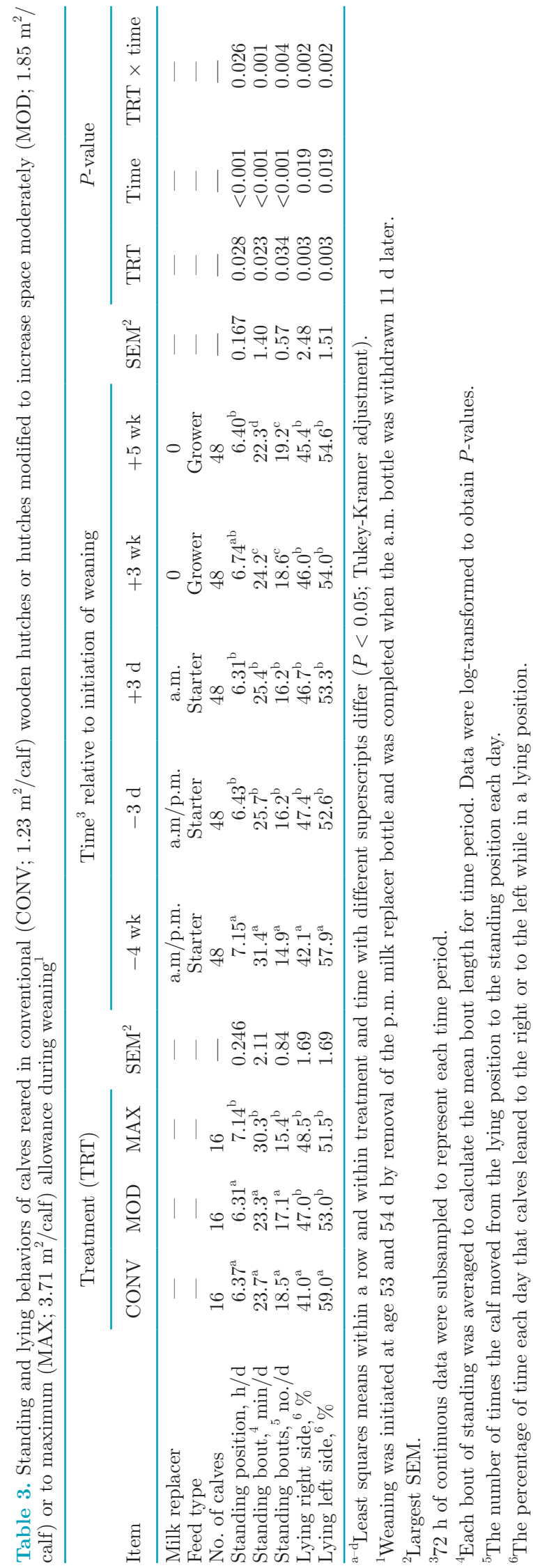

secretion compared with d 3 and preweaning measures at the 14-d sample. Although this could have resulted from many factors, we found it noteworthy that on $\mathrm{d}$ 14, calves were switched to the grower feed (Table 1), which has more roughage and legumes than calf starter and therefore more potential immunomodulators. Immunomodulators that stimulate IFN- $\gamma$ secretion may promote an immune system that can effectively ward off viruses and protozoa. We speculate that because CONV calves took longer to consume feed, they were exposed to less immunomodulators in the feed and therefore their leukocytes and erythrocytes were more sensitive to PHA. Similar to MOD calves, microbial exposure potentially played a role in IFN- $\gamma$ release among CONV calves; they were also not as clean as MAX calves.

\section{Neutrophil Function and Housing Systems}

The microbial and social environment of the hutches may have also contributed to the ex vivo neutrophil function and whole-blood bactericidal activity results (Kampen et al., 2006; Ezenwa et al., 2012). The MAX calves had the lowest percentage of neutrophils that had both $\mathrm{PG}+$ and $\mathrm{OB}+$ response to heat-killed E. coli $(P=0.002$; Table 3$)$, and their $\mathrm{PG}+\mathrm{OB}+$ neutrophils had the least oxidative burst and phagocytosis mean fluorescence intensity $(P<0.01$; Table 3$)$. Similarly to eosinophils, neutrophils can overrespond during an inflammatory response; excessive oxidative burst capacity may exacerbate the inflammatory response to tissue damage if neutrophils become necrotic. Paradoxically, if neutrophil phagocytosis is lessened, their capacity to efficiently clear infection is impeded (Paape et al., 2003; Hulbert and Moisá, 2016). In less sanitary conditions, neutrophils can become overstimulated when both MAMP and molecules from damaged tissue are present (danger-associated molecular patterns; Chang et al., 2004; Buckham Sporer et al., 2007; Hulbert and Moisá, 2016). A healthy neutrophil undergoes apoptosis, and therefore no danger-associated molecular patterns are released to exacerbate inflammation. A weak neutrophil will undergo necrosis, and then danger-associated molecular patterns recruit more inflammatory reaction. For the current study, it is unknown whether MAX hutch neutrophils had proper cell death after phagocytosis. We previously reported that MAX calves also had less $\mathrm{PG}+\mathrm{OB}+$ neutrophils after castration at age 3 wk compared with CONV calves, which was an indicator that the wound healing was likely localized and neutrophils were not overstimulated (Calvo-Lorenzo et al., 2017). In addition, the coats of MAX calves were cleaner and free of fecal matter during the first $3 \mathrm{wk}$ of life compared with CONV calves, and throughout the 
entire experiment MAX calves had limited exposure to neighboring calf feces, as the MAX hutch houses only 1 calf (Calvo-Lorenzo et al., 2016).

Nonetheless, we considered the possibility that the lack of social contact may have influenced neutrophil function, as allogrooming and tactile stimulation in neonatal animals influence immune regulation (Henricks et al., 1987; Costa et al., 2016). The bacteria for the neutrophils assays was heat killed, but these findings among neutrophil function reflected live bactericidal activity; the MAX calves tended $(P=0.098$; Table 2) to have the least ex vivo bactericidal activity of live bacteria. This finding suggests that MAX calf immunity may not be as competent as that of the other calves (Schäfer et al., 2008). As mentioned previously, MAX calves had a haptoglobin response when weaning was finalized, which indicated a stress response, but MOD calf haptoglobin did not change. Although scientists and extension agents promoted individual housing to impede enteric disease transmission (Dellmeier et al., 1985; Anderson, 1998; Moore et al., 2007), the CONV hutch system allows for nose-to-nose contact (CalvoLorenzo et al., 2016; Love et al., 2016). Nonetheless, panels prevent undesired cross-suckling behaviors that often increase at weaning (de Passillé, 2001). The MOD housing system allows for nose-to-nose contact, but the MAX housing system truly isolates tactile contact between calves.

Social interaction still may be needed for neutrophil regulation and to cope with stress. Although we speculated that the increase in standing time contributed to increased motivation to consume solid food, MAX calves may have also spent more time standing to attempt to gain access to a neighboring calf. Direct observations of grooming, social, and exploratory behaviors are needed to confirm this conclusion. An additional measure of immunity from the main experiment, however, suggests that MAX calves had better regulated immunity than CONV calves. We previously reported that $3 \mathrm{~d}$ after a subset of postweaned calves were exposed in vivo to an aerosolized, innocuous protein, ovalbumin, the MAX and MOD calves had less eosinophils migrate into the respiratory system (Calvo-Lorenzo et al., 2016). Neutrophils are typically the first responders to this in vivo treatment (Gershwin et al., 2011), and their cell death in the lungs then recruits other cells. Therefore, this finding may be an indirect indicator that MAX calf neutrophils were healthy, although the more sanitary environment made MAX calf neutrophils less activated.

\section{CONCLUSIONS}

Although the CONV hutch is economical from a material and land space standpoint, the system itself may be contributing to the primary concern over animal welfare; after $6 \mathrm{wk}$ of age, $\mathrm{CONV}$ calves need to be weaned and leave the hutches because they cannot freely turn around. The CONV hutch system appears to demotivate calves to consume feed at an early age. This may contribute to stress during the 2-step weaning process because CONV calves may not be as adapted to digesting large amounts of grains as calves with more space allowance (Dennis et al., 2018b). Therefore, one solution for improving welfare for calves raised in wooden hutches is to increase space allowance. For the current experiment, the MAX hutches provided space that likely helped calves stay motivated to be in an active state, but some of the decreased measures of immunity among MAX calves warrant concern and further investigation to rule out the possibility that the lack of tactile social interaction impeded immune resilience to pathogens and stressors. Nonetheless, MOD calves appeared to be the most ready for weaning because they ate feed at an early age, did not have a haptoglobin response to each step of weaning, and appeared to have immune resilience. Calves raised in MOD hutches possibly could be weaned and placed into pens at an earlier age (closer to the US average of $6 \mathrm{wk}$ ) to avoid restricting their ability to turn around freely. The increased space allowance in the MOD hutch system may cost more from a land resource standpoint; however, a faster turnover rate for hutched calves may make up for this cost if the calves are ready to be weaned at an earlier age than CONV calves.

\section{ACKNOWLEDGMENTS}

We appreciate the assistance of University of California, Davis, academics Roberta Franco, Clayton Neumeier, Sara E. Place, Kimberly Stackhouse-Lawson, Qian Wang, Vanessa Arias, Jamie Sherman, Monica VanKlompenberg, Veronica Arteaga, Jessica Botelho, Joseph Dorsch, Ashley Fowler, Connor Hoff, Benjamin Kasl, Lauren LeFort, Jacob Murphy, Nasario Ramos, Jessica Sampson, Alex Taylor, Tara Urbano, Jessica Varaitch-Scrase, Samantha Werth, Bruce Hoar, Alyssa Louie, Amanda Plunkett, Michael Tobias, Kevin Bauer, Jennifer Arnall, Cody Wohlman, Josh Ettlin, Joshua Krumheuer, Jessica Collier, Cameron Thompson, Gerry Johnson, James Moller, Dan Sehnert, Mark Rubio, Jose Villasenor, Frank Sauers, David Gall, Yongjing Zhao, and Yuee Pan for help associated with animal care and data collection. We also thank Cassandra Tucker, Eranda Rajapaksha, Yunzhi Luo, and Ashley Fowler for their support with the data logger standard operating procedures and data management. Funding and support for this project were provided by the California Cattlemen's Association (Sacramento), Western 
United Dairymen (Modesto, CA), and an anonymous Tulare County bull calf ranch (Tulare, CA). Additional statistical analyses and manuscript drafting from the overall experiment by L. Hulbert were funded through Kansas State University HA (Hatch Act of 1887) distributions representing the USDA-NIFA Multistate Project W-3173 (Impacts of Stress Factors on Performance, Health, and Well-Being of Farm Animals).

\section{REFERENCES}

Abdelfattah, E. M., M. M. Karousa, D. C. Lay Jr., J. N. MarchantForde, and S. D. Eicher. 2018. Short communication: Effect of age at group housing on behavior, cortisol, health, and leukocyte differential counts of neonatal bull dairy calves. J. Dairy Sci. 101:596-602.

Anderson, J. F. 1998. Biosecurity: A new term for an old conceptHow to apply it. Bov. Pract. 32:61-70.

Anderson, K. L., T. G. Nagaraja, J. L. Morrill, T. B. Avery, S. J. Galitzer, and J. E. Boyer. 1987. Ruminal microbial development in conventionally or early-weaned calves. J. Anim. Sci. 64:1215-1226.

Arthington, J. D., S. D. Eicher, W. E. Kunkle, and F. G. Martin. 2003. Effect of transportation and commingling on the acute-phase protein response, growth, and feed intake of newly weaned beef calves. J. Anim. Sci. 81:1120-1125.

Ballou, M. A., C. J. Cobb, L. E. Hulbert, and J. A. Carroll. 2011. Effects of intravenous Escherichia coli dose on the pathophysiological response of colostrum-fed Jersey calves. Vet. Immunol. Immunopathol. 141:76-83.

Berman, A. 2003. Effects of body surface area estimates on predicted energy requirements and heat stress. J. Dairy Sci. 86:3605-3610.

Bonk, S., O. Burfeind, V. S. Suthar, and W. Heuwieser. 2013. Technical note: Evaluation of data loggers for measuring lying behavior in dairy calves. J. Dairy Sci. 96:3265-3271.

Buckham Sporer, K. R., J. L. Burton, B. Earley, and M. A. Crowe. 2007. Transportation stress in young bulls alters expression of neutrophil genes important for the regulation of apoptosis, tissue remodeling, margination, and anti-bacterial function. Vet. Immunol. Immunopathol. 118:19-29.

Burciaga-Robles, L. O. 2015. Neonatal and young $(<205 \mathrm{~kg})$ feeding programs in calf-fed Holsteins. Abstract 516 in Proc. ADSA-ASAS Joint Annual Meeting, Orlando, FL. Accessed Jun. 1, 2018. http:/ /m.jtmtg.org/abs/t/65556.

California Attorney General. 2008. Proposition 2: Standards for confining farm animals initiative statute. Accessed Dec. 29, 2015. http://voterguide.sos.ca.gov/past/2008/general/title-sum/prop2 -title-sum.htm.

Calvo-Lorenzo, M. S., L. E. Hulbert, A. L. Fowler, A. Louie, L. J. Gershwin, K. E. Pinkerton, M. A. Ballou, K. C. Klasing, and F. M. Mitloehner. 2016. Wooden hutch space allowance influences male Holstein calf health, performance, daily lying time, and respiratory immunity. J. Dairy Sci. 99:4678-4692.

Calvo-Lorenzo, M. S., L. E. Hulbert, M. A. Ballou, A. L. Fowler, Y. Luo, K. C. Klasing, and F. M. Mitloehner. 2017. Space allowance influences individually housed Holstein bull calf innate immune measures and standing behaviors after castration at 3 weeks of age. J. Dairy Sci. 100:2157-2169.

Camiloti, T. V., J. A. Fregonesi, M. A. G. von Keyserlingk, and D. M. Weary. 2012. Short communication: Effects of bedding quality on the lying behavior of dairy calves. J. Dairy Sci. 95:3380-3383.

Carstensen, L., C. M. Røntved, and J. P. Nielsen. 2005. Determination of tumor necrosis factor-alpha responsiveness in piglets around weaning using an ex vivo whole blood stimulation assay. Vet. Immunol. Immunopathol. 105:59-66.

Chang, L. C., S. A. Madsen, T. Toelboell, P. S. Weber, and J. L. Burton. 2004. Effects of glucocorticoids on Fas gene expression in bovine blood neutrophils. J. Endocrinol. 183:569-583.
Costa, J. H. C., M. A. G. von Keyserlingk, and D. M. Weary. 2016. Invited review: Effects of group housing of dairy calves on behavior, cognition, performance, and health. J. Dairy Sci. 99:2453-2467.

de Passillé, A. M. 2001. Sucking motivation and related problems in calves. Appl. Anim. Behav. Sci. 72:175-187.

Dellmeier, G. R., T. H. Friend, and E. E. Gbur. 1985. Comparison of four methods of calf confinement. II. Behavior. J. Anim. Sci. 60:1102-1109.

Dennis, T. S., F. X. Suarez-Mena, T. M. Hill, J. D. Quigley, R. L. Schlotterbeck, and L. E. Hulbert. 2018a. Effect of milk replacer feeding amount, age at weaning, and method of reducing milk replacer to wean on digestion, performance, rumination, and activity in dairy calves 0 to 4 months of age. J. Dairy Sci. 101:268-278.

Dennis, T. S., F. X. Suarez-Mena, T. M. Hill, J. D. Quigley, R. L. Schlotterbeck, R. N. Klopp, G. J. Lascono, and L. E. Hulbert. 2018b. Effects of gradual and later weaning ages when feeding high milk replacer rates on growth, textured starter digestibility, and behavior in Holstein calves from 0 to 4 months of age. J. Dairy Sci. 101:9863-9875

Ezenwa, V. O., N. M. Gerardo, D. W. Inouye, M. Medina, and J. B. Xavier. 2012. Animal behavior and the microbiome. Science 338:198-199.

Færevik, G., and K. Tjentland., S. LøvikInger, L. Andersen, and K. E. Bøe. 2008. Resting pattern and social behaviour of dairy calves housed in pens with different sized lying areas. Appl. Anim. Behav. Sci. 114:54-64.

FASS. 1999. Guide for the Care and Use of Agricultural Animals in Research and Teaching. 1st ed. Federation of Animal Science Societies, Champaign, IL.

Finch-Arietta, M. B., and F. R. Cochran. 1991. Cytokine production in whole blood ex vivo. Agents Actions 34:49-52.

Fiol, C., M. Aguerre, M. Carriquiry, and R. Ungerfeld. 2017. Social dominance in prepubertal dairy heifers allocated in continuous competitive dyads: Effects on body growth, metabolic status, and reproductive development. J. Dairy Sci. 100:2351-2359.

Fisher, L. J., G. B. Peterson, S. E. Jones, and J. A. Shelford. 1985. Two housing systems for calves. J. Dairy Sci. 68:368-373.

Foote, M. R., B. J. Nonnecke, D. C. Beitz, and W. R. Waters. 2007. High growth rate fails to enhance adaptive immune responses of neonatal calves and is associated with reduced lymphocyte viability. J. Dairy Sci. 90:404-417.

Friend, T. H., G. R. Dellmeier, and E. E. Gbur. 1985. Comparison of four methods of calf confinement. I. Physiology. J. Anim. Sci. 60:1095-1101.

Fujiwara, M., J. Rushen, and A. M. de Passillé. 2014. Dairy calves adaptation to group housing with automated feeders. Appl. Anim. Behav. Sci. 158. https://doi.org/10.1016/j.applanim.2014.06.011.

Gershwin, L. J., M. L. Anderson, C. Wang, L. J. Berghaus, T. P. Kenny, and R. A. Gunther. 2011. Assessment of IgE response and cytokine gene expression in pulmonary efferent lymph collected after ovalbumin inhalation during experimental infection of calves with bovine respiratory syncytial virus. Am. J. Vet. Res. 72:134-145.

Gupta, S., B. Earley, and M. A. Crowe. 2007. Effect of 12-hour road transportation on physiological, immunological and haematological parameters in bulls housed at different space allowances. Vet. J. 173:605-616.

Haley, D. B., J. Rushen, and A. M. de Passille. 2000. Behavioural indicators of cow comfort: Activity and lying behaviour of dairy cows in two types of housing. Can. J. Anim. Sci. 80:257-263.

Heagy, W., K. Nieman, C. Hansen, M. Cohen, D. Danielson, and M. A. West. 2003. Lower levels of whole blood LPS-stimulated cytokine release are associated with poorer clinical outcomes in surgical ICU patients. Surg. Infect. (Larchmt.) 4:171-180.

Heegaard, P. M. H., D. L. Godson, M. J. M. Toussaint, K. Tjørnehøj, L. E. Larsen, B. Viuff, and L. Rønsholt. 2000. The acute phase response of haptoglobin and serum amyloid a (SAA) in cattle undergoing experimental infection with bovine respiratory syncytial virus. Vet. Immunol. Immunopathol. 77:151-159.

Henricks, P. A. J., G. J. Binkhorst, and F. P. Nijkamp. 1987. Stress diminishes infiltration and oxygen metabolism of phagocytic cells in calves. Inflammation 11:427-437. 
Hickey, M. C., M. Drennan, and B. Earley. 2003. The effect of abrupt weaning of suckler calves on the plasma concentrations of cortisol, catecholamines, leukocytes, acute-phase proteins and in vitro interferon-gamma production. J. Anim. Sci. 81:2847-2855.

Hulbert, L. E., J. A. Carroll, M. A. Ballou, L. C. Caldwell, A. N. Loyd, N. C. Burdick, R. C. Vann, T. H. Welsh Jr., and R. D. Randel. 2013. Sexually dimorphic stress and pro-inflammatory cytokine responses to an intravenous corticotropin-releasing hormone $(\mathrm{CRH})$ challenge of Brahman cattle following transportation. Innate Immun. 19:378-387. https://doi.org/10.1177/1753425912462752.

Hulbert, L. E., J. A. Carroll, N. C. Burdick, R. D. Randel, M. S. Brown, and M. A. Ballou. 2011. Innate immune responses of temperamental or calm cattle after transportation. Vet. Immunol. Immunopathol. 143:66-74. https://doi.org/10.1016/j.vetimm.2011.06 .025 .

Horvath, K. C., and E. K. Miller-Cushon. 2017. The effect of milkfeeding method and hay provision on the development of feeding behavior and non-nutritive oral behavior of dairy calves. J. Dairy Sci. 100:3949-3957.

Hulbert, L. E., and M. A. Ballou. 2012. Innate immune responses and health of individually reared Holstein calves after placement into transition pens 23 d after weaning. J. Dairy Res. 79:333-340.

Hulbert, L. E., C. J. Cobb, J. A. Carroll, and M. A. Ballou. 2011. The effects of early weaning on innate immune responses of Holstein calves. J. Dairy Sci. 94:2545-2556.

Hulbert, L. E., and S. J. Moisá. 2016. Stress, immunity and the management of calves. J. Dairy Sci. 99:3199-3216.

Hurnik, J. F., and N. J. Lewis. 1991. Body surface area, a reference for space allowance in confinement. Poult. Sci. 70:412-415.

Jensen, M. B., and R. Kyhn. 2000. Play behaviour in group-housed dairy calves, the effect of space allowance. Appl. Anim. Behav. Sci. 67:35-46.

Kampen, A. H., I. Olsen, T. Tollersrud, A. K. Storset, and A. Lund. 2006. Lymphocyte subpopulations and neutrophil function in calves during the first 6 mon of life. Vet. Immunol. Immunopathol. 113:53-63.

Kertz, A. F., T. T. M. Hill, J. D. Quigley III, A. J. Heinrichs, J. G. Linn, and J. K. Drackley. 2017. A 100-year review: Calf nutrition and management. J. Dairy Sci. 100:10151-10172.

Kim, M. H., J. Y. Yang, S. D. Upadhaya, H. J. Lee, C. H. Yun, and J. K. Ha. 2011. The stress of weaning influences serum levels of acute-phase proteins, iron-binding proteins, inflammatory cytokines, cortisol, and leukocyte subsets in Holstein calves. J. Vet. Sci. $12: 151-157$.

Kusnecov, A. W., and A. Rossi-George. 2002. Stressor-induced modulation of immune function: A review of acute, chronic effects in animals. Acta Neuropsychiatr. 14:279-291.

Ledgerwood, D. N., C. Winckler, and C. B. Tucker. 2010. Evaluation of data loggers, sampling intervals, and editing techniques for measuring the lying behavior of dairy cattle. J. Dairy Sci. 93:5129-5139.

Lefcourt, A. M., and T. H. Elsasser. 1995. Adrenal responses of Angus $\times$ Hereford cattle to the stress of weaning. J. Anim. Sci. 73:2669 2676.

Love, W. J., T. W. Lehenbauer, B. M. Karle, L. E. Hulbert, R. Anderson, A. L. Van Eenennaam, T. B. Farver, and S. S. Aly. 2016. Survey of dairy practices associated with respiratory health of preweaned calves on California dairies. J. Dairy Sci. 99:1-12.

Lynch, E. M., B. Earley, M. McGee, and S. Doyle. 2010. Effect of abrupt weaning at housing on leukocyte distribution, functional activity of neutrophils, and acute phase protein response of beef calves. BMC Vet. Res. 6:39-47.

Macaulay, A. S., G. L. Hahn, D. H. Clark, and D. V. Sission. 1995. Comparison of calf housing types and tympanic temperature rhythms in Holstein calves. J. Dairy Sci. 78:856-862.

Meale, S. J., S. Li, P. Azevedo, H. Derakhshani, J. C. Plaizier, E. Khafipour, and M. A. Steele. 2016. Development of Ruminal and fecal microbiomes are affected by weaning but not weaning strategy in dairy calves. Front. Microbiol. 7:582. https://doi.org/10 $.3389 /$ fmicb.2016.00582.

Mitra, R., R. Adamec, and R. Sapolsky. 2009. Resilience against predator stress and dendritic morphology of amygdala neurons. Behav. Brain Res. 205:535-543.

Moisá, S. J., S. S. Aly, T. W. Lehenbauer, W. J. Love, P. V. Rossitto, A. L. Van Eenennaam, S. C. Trombetta, E. M. Bortoluzzi, and L. E. Hulbert. 2018. Association of plasma haptoglobin concentration and other biomarkers with bovine respiratory disease status in pre-weaned dairy calves. J. Vet. Diagn. Invest. https://doi.org/10 $.1177 / 1040638718807242$.

Moore, D. A., K. Heaton, S. Poisson, and W. M. Sischo. 2012. Dairy calf housing and environment: The science behind housing and on-farm assessments. Publ. no. EM045E. Washington State University Extension, Pullman.

Murata, H., and T. Miyamoto. 1993. Bovine haptoglobin as a possible immunomodulator in the sera of transported. Br. Vet. J. 149:277-283

National Farm Animal Care Council (NFACC). 2009. Code and Practice for the Care and Handling of Dairy Cattle. Dairy Farmers of Canada and the National Farm Animal Care Council.

Paape, M. J., D. D. Bannerman, X. Zhao, and J. W. Lee. 2003. The bovine neutrophil: Structure and function in blood and milk. Vet. Res. 34:597-627.

Schäfer, M., P. Sharp, V. J. Brooks, J. Xu, J. Cai, N. S. Keuler, S. F. Peek, R. G. Godbee, R. D. Schultz, and B. J. Darien. 2008. Enhanced bactericidal activity against Escherichia coli in calves fed Morinda citrifolia (Noni) puree. J. Vet. Intern. Med. 22:499-502.

Schaefer, D. M. 2005. Yield and quality of Holstein beef. Pages 323333 in Proc. Managing and Marketing Quality Holstein Steers. R. Tigner and J. Lehmkuhler, ed. Wisconsin Agric. Service Assoc., Madison.

Shamri, R., J. J. Xenakis, and L. A. Spencer. 2011. Eosinophils in innate immunity: An evolving story. Cell Tissue Res. 343:57-83.

Sharon, K. P., L. E. Hulbert, and M. A. Ballou. 2019. The effects of plane of milk replacer nutrition on the health, behavior, and performance of high-risk Holstein bull calves from a commercial calf ranch. Animal In press.

Sorrells, S. F., and R. M. Sapolsky. 2007. An inflammatory review of glucocorticoid actions in the CNS. Brain Behav. Immun. 21:259272

Tapkı, I. A. Ş., and A. G. Önal. 2006. Effect of space allowance on behaviour of newborn milk-fed dairy calves. Appl. Anim. Behav. Sci. 99:12-20. https://doi.org/10.1016/j.applanim.2005.09.006.

Terosky, T. L., L. L. Wilson, C. L. Stull, and W. R. Stricklin. 1997. Effects of individual housing design and size on special-fed Holstein veal calf growth performance, hematology, and carcass characteristics. J. Anim. Sci. 75:1697-1703.

Tucker, C. B., N. R. Cox, D. M. Weary, and M. Špinkad. 2009. Laterality of lying behaviour in dairy cattle. Appl. Anim. Behav. 120:125-131.

Walker, W. L., W. B. Epperson, T. E. Wittum, L. K. Lord, P. J. Rajala-Schultz, and J. Lakritz. 2012. Characteristics of dairy calf ranches: Morbidity, mortality, antibiotic use practices, and biosecurity and biocontainment practices. J. Dairy Sci. 95:2204-2214.

Wardynski, F. 2012. Raising dairy steer calves for profitable beef production. Accessed Jun. 1, 2016. http://msue.anr.msu.edu/news/ raising_dairy_steer_calves_for_profitable_beef_production.

Wilson, L. L., T. L. Terosky, C. L. Stull, and W. R. Stricklin. 1999. Effects of individual housing design and size on behavior and stress indicators of special-fed Holstein veal calves. J. Anim. Sci. 77:1341-1347.

Wolf, C. A. 2003. Custom dairy heifer grower industry characteristics and contract terms. J. Dairy Sci. 86:3016-3022. 